\title{
Deploying, Updating and Running Electric Vehicles Charging Facilities in the US
}

Name: Jianan Wang

Email: jwang249@hawk.iit.edu CWID: A20412640

Instructor: Prof. Bruce Gockerman 


\section{Executive Summary}

The target of this report is to conclude the situation of electric vehicles and charging stations, a part of infrastructure system, explain some of the application and technical issues of charging and batteries, and give some details of strategic competitiveness planning and prediction about the future.

The electric vehicles, or also called plug-in cars, are coming to more and more people`s lives. Up to now, there are an estimated 270 million registered passenger vehicles in the US. Based on the expert's conservative estimation in Appendix A, they'll account for 5 percent of all vehicles by the late 2020s and 36 percent by the early 2040s. (Stephen Leahy, 2017) However, so far the US has about 120,000 gas stations while charging stations are only 10,000. (James Larminie, 2012) Most of them are slow charging piles failing to meet the requirements of efficiency. That's why we need to enlarge and upgrade existing charging facilities.

Fast charging facilities have greater construction value. In the US, they are separated to 3 levels. Level 1 is based on $110 \mathrm{~V} \mathrm{AC}$ city electricity system and very slow. Level 2 has special power supply line of $240 \mathrm{~V} \mathrm{AC}$ and the speed is OK. Level 3 chargers carry a charge of 480V DC, using a 100-350A dedicated breaker with special grounding equipment, and are the fastest piles. Most of charging facilities in the world are Level 1 and usually owned by residents privately. Few of them are Level 2. Level 3 piles are much less.

Chicago, a big and prospective city in the US, is the research object of this paper. One target of my strategies is to let Chicago build more fast piles or upgrade original piles to faster ones, and deal with the replaced piles in order to keep a sustainable and efficiency charging facilities infrastructure development. Then, more details of cost will be given for Cost-Benefit Analysis. These strategies can also be implemented in the US, maybe other countries.

The last part of the paper is about a possible future tendency - removable batteries that may bring some new revolutions to the current charging technology.

\section{Introduction}

The electric vehicles, or may be called plug-in cars, are continuing to make waves across the modern vehicle industry. So far electric vehicles can be distorted by pure and hybrid, which are usually called Plug-in Electric Vehicles and Plug-in Hybrid Electric Vehicles. (James Larminie, 2012) The electric vehicles have contribution to protect environment through reducing carbon emission and pollution by improving the using efficiency of fuel and electricity, and indirect use of pollution-free energy, like wind energy, waterpower and nuclear. 
Electric vehicles need electricity as fuel, so the charging facilities are becoming an important infrastructure. Up to now, the US has about 120,000 gas stations while charging stations are only 10,000. Unfortunately, most of them are slow charging piles, like Level 1 or 2. (James Larminie, 2012) So sufficient charging facilities, especially Level 3 piles, should be deployed in order to meet the increasing of electric vehicles quantity. However, we have to consider about many following problems. This paper introduced some simple technical details of batteries and all levels of stations, and discussed about where and how to deploy, cost and benefit, safety issues and other challenges, and gave a prediction of what the future tendency will be.

\section{General \& Specific Description of the Infrastructure topic}

- Classification of charging stations. Based on the EVSE, there are 3 levels of charging piles. Level 1 is based on $110 \mathrm{~V}$ AC domestic electricity circuit in the US. With a dedicated 15 A circuit, the capacity of these piles are about $1.95 \mathrm{~kW}$. Level 2 provides a $240 \mathrm{~V}$ AC and up to $30 \mathrm{~A}$ current in charging, up to about $6.6 \mathrm{~kW}$ charging power. Level 3, also called fast piles, can provide about 480V DC and 100-350 A current high speed charging, which means 48-168 kW charging power and at most 23 times faster than Level 2. For safety reason, the battery will only be charged to $50 \%-80 \%$ through Level 3 piles. (Daniel Chang, 2012)

- Category of electric vehicles. Plug-in Electric Vehicles (PEV) and Plug-in Hybrid Electric Vehicles (PHEV). A plug-in electric vehicle (PEV) is any motor vehicle that can be recharged from an external source of electricity, such as charging piles, and the electricity stored in the rechargeable battery packs drives or contributes to drive the wheels. A plug-in hybrid electric vehicle (PHEV) is a hybrid electric vehicle whose battery can be recharged by plugging it in to an external source of electric power as well by its on-board engine and generator, and these on-board engine generators are mostly propelled by gas and diesel. Apart from that, many PHEVs can also collect electricity from accelerating and braking. Owing to the difference of hybrid technology, some need charging but not often, while others don`t need it anymore. (David Sandalow, 2009; James Larminie, 2012)

- Charging types. There are four mainstream modes: Domestic socket and extension cord; Domestic socket and cable with a protection device; Specific socket on a dedicated circuit; Direct current (DC) connection for fast recharging. The first two modes are for level 1 because of the limitation of the domestic electricity grid. The latter two modes are for level 2 and 3 charging stations in each. (Daniel Chang, 2012)

- Category of batteries. Most of the rechargeable batteries are made of Lithium (Li) cathode, metal oxidation compounds anode, electrolytes, and other materials holding the structure. Based on the type of electrolytes, they can be separated by Li-ion (using liquid electrolyte to conduct ions) and Li-polymer (using solid and polymermade electrolyte to conduct ions). (Norman Greenwood, 1997) 
- Benefits of promoting EVs and charging stations. It can not only save fossil fuels for other more useful applications, but also create a better environment for living by reducing the emission of greenhouse gases and pollution. (Albert Lam, 2013)

\section{Literature Review}

Fossil fuels are running out day by day, so seeking new abundant energy sources is very necessary. One of the major fossil fuel consumptions is transportation. Many vehicles are powered by petrol now. A major consequence of burning fossil fuels is the release of tremendous amount of harmful gases, which partially constitutes the global warming effect and deteriorates people's health. Electricity is considered as the most universal form of energy, which can be transformed from and to another form effectively. Electrification of transportation, like deployment of electric vehicles (EVs), can not only reduce our consumption on fossil fuels, but also create a better environment for living. Therefore, EVs will become the major components in the future transportation system. (Albert Lam, 2013)

For site owners interested in installing EV chargers, three charger options are available: Level 1, Level 2, and Level 3 (also known as the DC fast charger). A Level 1 charger consists of simply a special cord that plugs an EV to a traditional 110-volt (AC) plug with a dedicated 15-amp circuit. The capacity of these chargers are $1.95 \mathrm{~kW}$. A Level 2 charger is a standalone box that can be mounted to a wall and wired directly to an electrical panel. It carries a charge of 240-volt (AC) with a dedicated 30-amp circuit and. The maximum power of a Level 2 charger is $6.6 \mathrm{~kW}$. Level 3 chargers carry a charge of 480 volt (DC) using a 100-350 amp dedicated breaker with special grounding equipment. (Daniel Chang, 2012)

A plug-in electric vehicle (PEV) is any motor vehicle that can be recharged from an external source of electricity, such as wall sockets, and the electricity stored in the rechargeable battery packs drives or contributes to drive the wheels. (David Sandalow, 2009) A plug-in hybrid electric vehicle (PHEV) is a hybrid electric vehicle whose battery can be recharged by plugging it in to an external source of electric power as well by its internal engine or other generators. (James Larminie, 2012)

The depleted battery module is removed from the electric powered vehicle and replaced with a battery module including a fully charged battery. The driver is then charged for the battery module including the fully charged battery. (George Chaney, 2007)

If electric vehicles are adopted at that pace, say Hasanov and Reda Cherif of IMF and Aditya Pande of Georgetown, they'll account for 5 percent of all vehicles by the late 2020s and 36 percent by the early 2040s. The researchers call that the "slowadoption scenario." (Stephen Leahy, 2017) 


\section{Statement of Challenges and Opportunities}

- Charging speed. No one prefers slower charging. Assume that the battery has 70 $\mathrm{kWh}$ electricity capacity, if the pile is Level 2 that can provide $7.2 \mathrm{~kW}$ charging power, it will need about 10 hours to charge form empty to full ignoring the loss from charging. Before the popular of Level 3 piles and make better use of existing gas stations, the PHEVs will be a feasible solution to cater the need of cost, charging speed and existing infrastructures. (Daniel Chang, 2012)

- Safety and technology problems. Everyone is pursuing for longer endurance mileage, so the battery capacity is increasing. This poses a challenge to the charging power, otherwise the charging time will be extended. And charging voltage is certain in every level of the piles, so higher current means higher charging power. However, high current will make facilities overload and aging ahead of time, and make batteries overheat that may heat liquid electrolyte to gas or make polymer release gas by heat decomposing. Then the sealed battery structure will be broken, air comes in and reacts with battery internal materials like Lithium (Li), and finally causes serious explosion. (James Larminie, 2012)The Standard Electric Potential of $\mathrm{Li}^{+} / \mathrm{Li}$ is $-3.04 \mathrm{~V}$, and the burning enthalpy of $\mathrm{Li}$ is about $43 \mathrm{KJ} / \mathrm{g}$, proving that the $\mathrm{Li}$ is a high energy density material. (Norman Greenwood, 1997)

- Where and how to deploy and develop charging piles. Let's choose Chicago as a simple. In Chicago there are about 271 Level 2 charging stations and 57 Level 3 charging stations. (Source: https://chargehub.com/ )In the future more and more charging stations will be built, and most of them will be in Level 3. However, the city has to deal with these old Level 2 piles. In my opinion, we can move some of them to low requirement places, such as parking lots, or sell them to nearby counties and towns, or people or companies who have this demand. And new Level 3 piles will replace their original places. Moreover, some of the gas stations can be replaced by charging stations because there will be less petrol vehicles in the future, and people don't need such a large number of them anymore.

- The cost and benefit problems. The faster, the better. No doubt Level 3 piles have more commercial potential than other piles, but we have to think about the cost and benefit problems. The price of electricity is about $\$ 0.16$ per $\mathrm{kWh}$ in Chicago, maybe some discount if buying a lot. A typical Level 2 pile costs $\$ 1,000-\$ 1,200$, while a Level 3 station may cost $\$ 50,000-\$ 100,000$, not including the land rent rates. What's more, we didn't include annually maintenance costs in our analysis, but studies suggest about $\$ 300$ for a public Level 2 station and \$1,000-\$2,000 for a Level 3 station. Obviously, Level 3 stations cost a lot in all kinds of aspects, which needs operators to think about how to set the price, how many vehicles will come to the station per day, how to balance cost and benefit, and when they will start getting revenues. (Daniel Chang, 2012) 


\begin{tabular}{|c|c|c|c|c|c|}
\hline & $\begin{array}{l}\text { Level } 2 \\
\text { Home }\end{array}$ & $\begin{array}{l}\text { Level } 2 \\
\text { Parking } \\
\text { Garage }\end{array}$ & $\begin{array}{l}\text { Level } 2 \\
\text { Curb- } \\
\text { side }\end{array}$ & $\begin{array}{l}\text { DC Fast } \\
\text { Charging }\end{array}$ & Description/Key Assumptions \\
\hline $\begin{array}{l}\text { Charge } \\
\text { station } \\
\text { hardware }\end{array}$ & $\begin{array}{l}\$ 450- \\
\$ 1,000\end{array}$ & $\begin{array}{l}\$ 1,500- \\
\$ 2,500\end{array}$ & $\begin{array}{l}\$ 1,500- \\
\$ 3,000\end{array}$ & $\begin{array}{l}\$ 12,000- \\
\$ 35,000\end{array}$ & \\
\hline $\begin{array}{l}\text { Electrician } \\
\text { Materials }\end{array}$ & $\begin{array}{l}\$ 50- \\
\$ 150\end{array}$ & $\begin{array}{l}\$ 210- \\
\$ 510\end{array}$ & $\begin{array}{l}\$ 150- \\
\$ 300\end{array}$ & $\begin{array}{l}\$ 300- \\
\$ 600\end{array}$ & \multirow{2}{*}{$\begin{array}{l}\text { - } \$ 1.50-2.50 / \mathrm{ft} \text { for conduit and wire, plus } \\
\text { misc other materials } \\
\text { - } \$ 50-80 / \text { hour (per dist?) } \\
\text { - } \$ 500-1000 \text { if new breaker is required } \\
\text { - Assume } 2 x \text { electrical cost for level } 3\end{array}$} \\
\hline $\begin{array}{l}\text { Electrician } \\
\text { Labor }\end{array}$ & $\begin{array}{l}\$ 100- \\
\$ 350\end{array}$ & $\begin{array}{l}\$ 1,240- \\
\$ 2,940\end{array}$ & $\begin{array}{l}\$ 800- \\
\$ 1,500\end{array}$ & $\begin{array}{l}\$ 1,600- \\
\$ 3,000\end{array}$ & \\
\hline $\begin{array}{l}\text { Other } \\
\text { Materials }\end{array}$ & & $\begin{array}{l}\$ 50- \\
\$ 100\end{array}$ & $\begin{array}{l}\$ 50- \\
\$ 150\end{array}$ & $\begin{array}{l}\$ 100- \\
\$ 400\end{array}$ & \multirow{2}{*}{$\begin{array}{l}\text { - } \$ 25-100 / \mathrm{ft} \text { for trenching/boring- } \\
\text { depends on surface, soil, and underground } \\
\text { complexity } \\
\text { - Mounting, signage, protection, and } \\
\text { restoration also included here, but don't } \\
\text { usually contribute more than a few } \\
\text { hundred dollars }\end{array}$} \\
\hline Other Labor & & $\begin{array}{l}\$ 250- \\
\$ 750\end{array}$ & $\begin{array}{l}\$ 2,500- \\
\$ 7,500\end{array}$ & $\begin{array}{l}\$ 5,000- \\
\$ 15,000\end{array}$ & \\
\hline Transformer & NA & NA & NA & $\begin{array}{l}\$ 10,000- \\
\$ 25,000\end{array}$ & - $480 \mathrm{~V}$ transformer installed by utility \\
\hline Mobilization & $\begin{array}{l}\$ 50- \\
\$ 200\end{array}$ & $\begin{array}{l}\$ 250- \\
\$ 500\end{array}$ & $\begin{array}{l}\$ 250- \\
\$ 500\end{array}$ & $\begin{array}{l}\$ 600- \\
\$ 1,200\end{array}$ & $\begin{array}{l}\text { - Home: } 1-3 \text { hours of electrician time for a } \\
\text { home installation } \\
\text { - Public: } \$ 250-500 \text { of time for } 1-2 \\
\text { electricians and other labor. We found that } \\
\text { the work could usually be completed in a } \\
\text { single visit from each contractor. }\end{array}$ \\
\hline Permitting & $\$ 0-\$ 100$ & $\begin{array}{l}\$ 50- \\
\$ 200\end{array}$ & $\begin{array}{l}\$ 50- \\
\$ 200\end{array}$ & $\begin{array}{l}\$ 50- \\
\$ 200\end{array}$ & $\begin{array}{l}\text { - Varies city to city, often a flat fee for one or } \\
\text { several stations }\end{array}$ \\
\hline
\end{tabular}

(Data source: Daniel Chang, 2012)

\section{Summary and Conclusions}

The previous parts talked about many stuff of charging stations, like the classification and where and how to build them. Besides, it also showed us some technical details of batteries and piles, and pointed out some challenges of them, like safety issues and Cost-Benefit, and give discussion on the impacts and possible strategies for the city. Everyone likes faster charging experience, and electric cars can also bring a lot of environmental and economic benefits. But for the operators, or the government bureaus responsible for infrastructure, running charging stations is more like a game among technology, safety, market, Cost-Benefit and strategic planning. They have to think highly of that.

\section{Future Study}

Operating charging stations have to face many problems, like technical feasibility, market factors and Cost-Benefit. In technical feasibility part, speed and safety are contradictory under current technologies. High current brings more heat and overload on the facilities.

Inspired by a patent (No. US 7,201,384 B2), one of the feasible ways is to develop removable battery technology. (George Chaney, 2007) If the batteries of electric vehicles were removable, charging stations staffs could replace the empty batteries to pre-charged full ones so that customers would save a lot of time from waiting for charging. And batteries are all filled in advance, there is no need to worry about the 
safety problems caused by fast charging. A feasible pattern is in Appendix B.

Assume that a customer buys a brand new electric vehicle with a brand new battery, but he may meet a used battery which takes place of his new one in charging station. Obviously it's unfair for him. Meanwhile, it's very hard for many vehicle manufactories to run charging stations around the US, and these are not their duty, too. Even Tesla, its plan is just running about 1,000 fast charging stations, 20 per state in average, in the entire US, and of course it is too less to meet the market demand. (Source: https://www.tesla.com/ ) In view of this, selling vehicles and batteries separately is more proper in this mode, which means batteries and charging stations will be run together by some third-party companies.

However, this mode will also face to new challenges. First of all, so far battery technologies are core and competitive technologies of electric vehicle manufactories, few of them will be glad to release them to other companies. And it's also very hard to unify the battery interface connecting to the vehicle, too. Second, if the vehicles encounter breakdown, who should be responsible for main part of that? Low quality battery and poor battery maintaining will cause that, so do daily driving and other factors. The last challenge is about maintaining and refurbishing batteries. Keeping low electricity for a long time will hurt the battery capacity a lot. According to these challenges, this mode still need thinking deeply and amending a lot.

\section{References}

Chaney G. (2007). Electric vehicle chassis with removable battery module and a method for battery module replacement. United States Patent. No. US 7,201,384 B2.

Chang D. et al. (2012). Financial Viability of Non-Residential Electric Vehicle Charging Stations. Luskin Center for Innovation.

Greenwood N., \& Earnshaw A. (1997). Chemistry of the Elements (Second Edition). Butterworth-Heinemann. ISBN: 978-0-7506-3365-9.

Leahy S. (2017). Electric Cars May Rule the World's Roads by 2040. National Geographic. URL: https://news.nationalgeographic.com/2017/09/electric-carsreplace-gasoline-engines-2040/

Lam A., Leung Y., \& Chu X. (2013). Electric vehicle charging station placement. 2013 IEEE International Conference on Smart Grid Communications, Vancouver, BC, 2013, pp. 510-515. doi: 10.1109/SmartGridComm.2013.6688009.

Larminie J., \& Lowry J. (2012). Electric Vehicle Technology Explained. WILEY. ISBN: 9781119942733. 
Sandalow D, et al. (2009). Plug-In Electric Vehicles: What Role for Washington? (1st. ed.). The Brookings Institution. pp. 2-5. ISBN 978-0-8157-0305-1.

9. Appendices

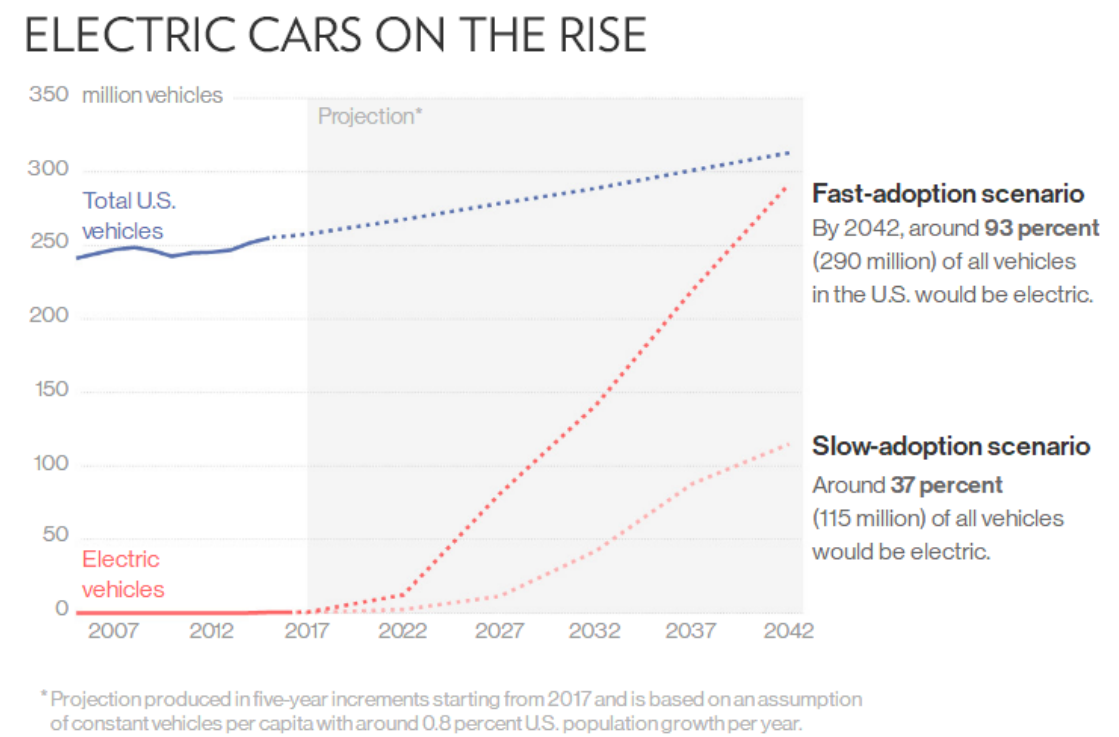

Appendix A. Future growth scenario of electric vehicles in the US. (Source: https://news.nationalgeographic.com/2017/09/electric-cars-replace-gasolineengines-2040/ )

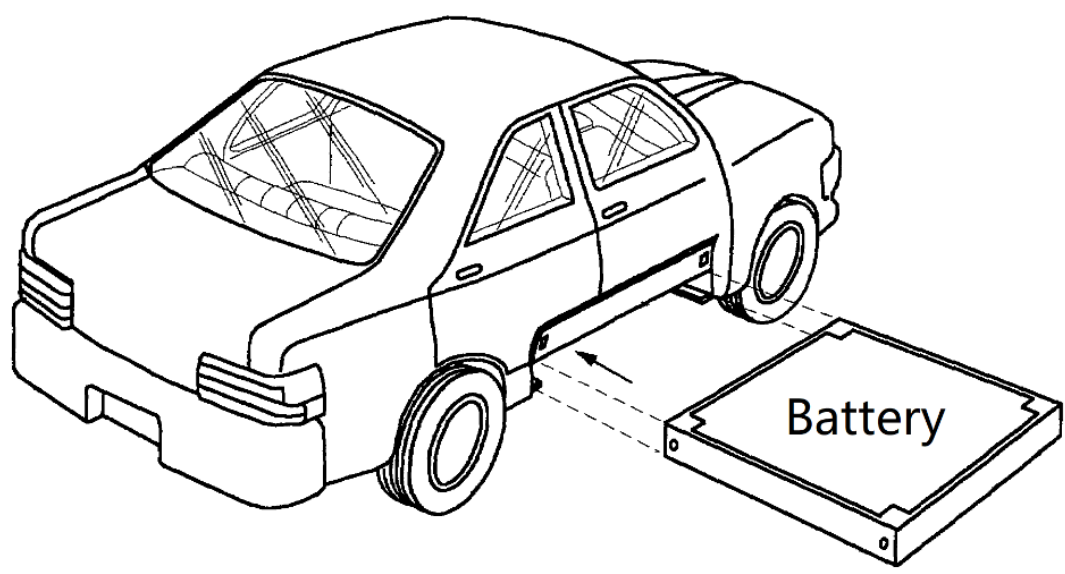

Appendix B. Removable Battery Model (Source: Patent, US7201384B2, with some modification) 